\title{
Conceptual Framework: Factors Affecting for Workplace Job Performances
}

\author{
J.A.Prasansha Kumari, \\ Senior Lecturer, Department of Economics, University of Kelaniya, Sri Lanka
}

\begin{abstract}
Job performance have identified as the key element at workforce performance. The purpose of this study is to initially construct a conceptual framework of factors affecting job performance. Information were collected from secondary sources. The study revealed that motivation, skills, satisfaction directly affecting for job performance at work place while rewards moderates to all three main factors to jobperformance
\end{abstract}

Keywords: Motivation, Skills, Satisfaction, Reward, Job performance

\section{Introduction}

Service industry have increased the need for motivating employees past recent (Saeid A.,M,2013. Different factors affected for job performance at the work place. Job performance assesses that a person performs a job well ( Iqbal.A et al, 2015). One of the elements that is estimate is the employees' performance through their productivity level. Hence, job performance is a significant factor for any company, performance of works should improve by the management for do their duties more effectively.

Business companies should provide motivation factors to their employee for significant achievement of their goals (Aarabi M.S et al, 2013). During the last few decades, human resource managers, academics have been interested to study on factors affecting for employees performance level According to the many past researches, The factors that are determined to affect the job performance include working hours, trainings, communication barriers, stress and financial rewards( Iqbal.A et al, 2015)). Same factors are described in different previous studies that affect the performance of employees at work place.

Skills, motivation, satisfaction and rewardsare significant factors for job performance of employee.There is a strong relationship between skills and employees performance. Trained employees work with high efficiency. It is increase the final output of the organization. Motivation is the important factor for increasing job performance at a workplace. Motivational factors such as organizational climate, intensives, and trainings considered a great motivator for the employees. There is a significant relationship between financial rewards and employees performance. If the performance is backed by financial rewards, then employees work more energetically at the work place .Rewards increase the employees' commitment which ultimately results in good performance. Assigning financial benefits result in the positive performance of employees at work.

\section{ProblemStatement}

Employee performance indicates the "effectiveness of employee's specific actions that contribute to attain organizational goals" (Iqbal.A et al, 2015)). According to many previous researches, there exist many common and different factors for job performance. Human Recourse Managers in business companies face challenges to manage motivational factors of their employees by satisfying their personal and career needs in order to enhance their job performance (Alonso and Lewis, 2001)Indeed, most researchers(Brewer and Selden, 2000). found that many companies in the world aim on factors for performance of the employees and incentives that can effect toward their job performance and their impact on productivity of companies This study is intend to identify the factors affecting for employee performance and their impact of output of the organization. The research focuses on exploring variables that drive; employees' performance.

\section{Research Question}

Base on research objectives and problem statement this study aims to address the following problem: What are the factors that affecting for job performance at a work place to increase productivity of companies?

\section{Objectives}

According to the problem statement the study aim to identify,

1. Identify the factors that are determined to affect job performance in order to increase the productivity in a business company

2. Exploring the variables that drive job performance and develop the conceptual framework 


\section{Materials and Methods}

This study focused on identify the factors affecting workforce job performance on the basis of the investigated variables in the recent literature on job performance to advance in this research. The secondary data collected in this study include book, journals, relevant publication, and websitesonline databases.

\section{Conceptual Framework}

The research study conceptualized out on the factors (skills, satisfaction, motivation) as independent variables and job performance as dependent variables as illustrated below. Rewards have identified as the moderates satisfaction, skills and motivation to job performance factor. Based on the statement, a theoretical framework has been developed to represent the relationship between three different factors and job performance.

\section{Job Performance:}

According to Borman and Motowidlo (1993) divided performance into two parts as task and contextual performance. Task performance was defined asthe "effectiveness with which job incumbents perform activities thatcontribute to the organization's technical core "(Borman and Motowidlo1997). Contextual performance was defined as "performance that is notformally required as part of the job but that helps shape the social andpsychological context of the organization" (Borman and Motowidlo,1993).

\section{Motivation:}

DeCenzo and Robbins (1996) define a motivation as the "willingness or desire to do something, conditioned by the activity or the ability to satisfy some needs" Mortivatio is one of key factor for the increasing job performance. Many enterprises have widely concerned the motivation of their employee in order to achieve the organizational targets. (Kamery, 2004; Ekerman, 2006).

\section{Satisfaction:}

Job satisfactionhas been defined as "feelings or affective responses to facets ofthe (workplace) situation" (Smith, Kendall, \& Hulin, 1965). Recently, researchers. (Kamery, 2004; Ekerman, 2006) have identified that job satisfaction is a one of key phenomenon to described the job performance thus, the organization concerned of their employee job satisfaction in order to fulfill the organization goals

Skills:

Skills development is important for success of the organization objectives, Skills development in the workplace is a real world phenomenon with a real impact on productivity. (Arrow, 1962) Skills form the human capital of an economy. According to Hanushek,Schwerdt, Wiederhold, \&Woessmann, 2014 skills can be divided in to two parts or numeracy skills (such as literacyor numeracy skills) and non-cognitive (such as physical or soft skills). Cognitive skills positively effect in the work place.

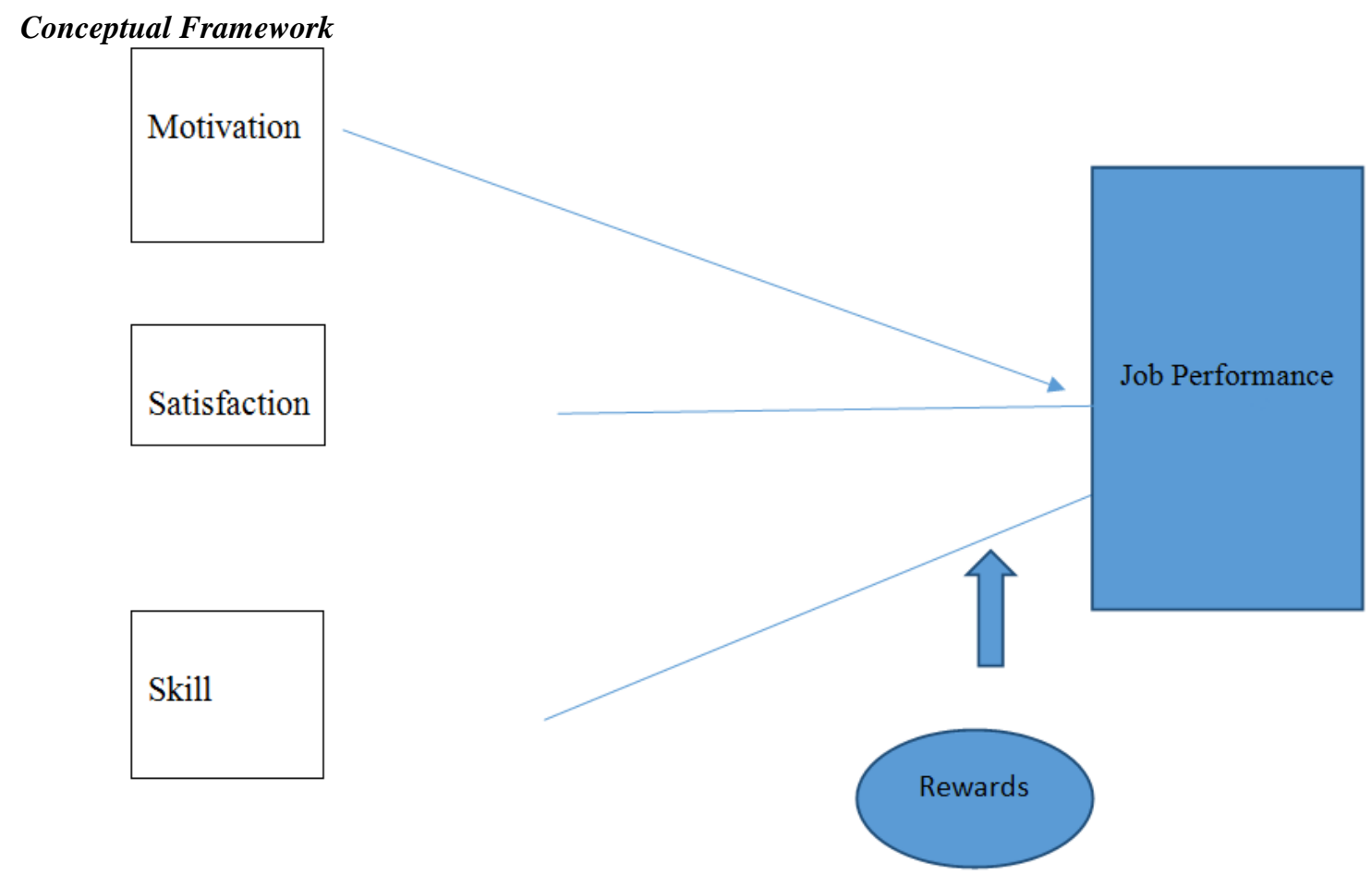




\section{Hypothesis development}

Base on the theoretical framework research hypothesis as follows,

$\mathrm{H} 1$ :There is a positive relationship betweenmotivation and job performance

H2: Satisfaction lead to job performance

H3: There is a positive relationship between skill and job performance

H4: Rewards moderates the motivation to job performance

H5:Rewards moderates the satisfaction to job performance

H6: Rewards moderates the skills to job performance

\section{Conclusion}

The study aims to review existing studies to investigate factorsaffecting job performance. It is revealed that skills, satisfaction and motivation significant factors to increase the job performance. Skills, satisfaction, motivation lead to workplace performance and it is directly affect to the organization productivity. Rewards moderates to motivation, skills and satisfaction to job performance.

\section{References}

[1]. Alonso, P., \& Lewis, G. B. (2001). Public Service Motivation and Job Performance Evidence from the Federal Sector. The American Review of Public Administration, 31(4), 363-380. http://dx.doi.org/10.1177/02750740122064992

[2]. Arrow, K. J. (1962). "The economic consequences of learning by doing." The Review of Economic Studies 29(3): 155 - 173.

[3]. Borman, W. C. and Motowidlo, S. J. (1993) Expanding the criterion domain to include elements of contextual performance. InmPersonnel Selection in Organizations (N. Schmitt \& W. C.Borman, eds), pp. 71-98. San Francisco: Jossey-Bass.

[4]. Brewer, G. A., Selden, S. C., and Facer II, R. L. (2000) Individual conceptions of public service motivation. Public Administration Review, 60(3): 254-264.

[5]. DeCenzo, D. A., \& Robbins, S. P. (1996). Human resources management. New York: John Wiley \& Sons, Inc.

[6]. Hanushek, E. A., \&Woessmann, L. (2014). The knowledge capital of nations. Book manuscript.

[7]. Hulin, C.L., and P.C. Smith (1965). A Linear Model Of Job Satisfaction. Journal Of Applied

[8]. Iqbal A, 2015, Factors affecting the employee's performance a case study of banking sector in Pakistan, uropean Journal of Business and Social Sciences, Vol. 4, No. 08, P.P. 309 - 318, URL: http://www.ejbss.com/recent.aspx

[9]. Kamery, R. H. (2004). Motivational Techniques for Positive Reinforcement: A Review. Allied AcademiesInternational Conference. $8(2), 91-96$ 